$$
\text { CONF-960569--22 }
$$

GA-A22357

\title{
FIRST MEASUREMENTS OF ELECTRON TEMPERATURE AND DENSITY WITH DIVERTOR THOMSON SCATTERING IN RADIATIVE DIVERTOR DISCHARGES ON DIII-D
}

\author{
by \\ S.L. ALLEN, D.N. HILL, T.N. CARLSTROM, D.G. NILSON \\ R.E. STOCKDALE, C.L. HSIEH, T.W. PETRIE, A.W. LEONARD, \\ D. RYUTOV, G.D. PORTER, R. MAINGI, M.R. WADE, R. COHEN, \\ W. NEVINS, M.E. FENSTERMACHER, R.D. WOOD, C.J. LASNIER, \\ W.P. WEST, and M.D. BROWN
}

RECEIVED

APR 141997

$08 T 1$

Dostrum of mow

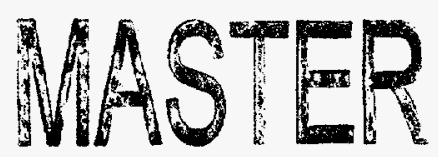

OCTOBER 1996 


\section{DISCLAIMER}

This report was prepared as an account of work sponsored by an agency of the United States Government. Neither the United States Government nor any agency thereof, nor any of their employees, makes any warranty, express or implied, or assumes any legal liability or responsibility for the accuracy, completeness, or usefulness of any information, apparatus, product, or process disclosed, or represents that its use would not infringe privately owned rights. Reference herein to any specific commercial product, process. or service by trade name, trademark, manufacturer, or otherwise, does not necessarily constitute or imply its endorsement, recommendation, or favoring by the United States Government or any agency thereof. The views and opinions of authors expressed herein do not necessarily state or reflect those of the United States Government or any agency thereof. 


\section{DISCLAMMER}

Portions of this document may be illegible in electronic image products. Images are produced from the best available original document. 


\title{
FIRST MEASUREMENTS OF ELECTRON TEMPERATURE AND DENSITY WITH DIVERTOR THOMSON SCATTERING IN RADIATIVE DIVERTOR DISCHARGES ON DIII-D
}

\author{
by \\ S.L. ALLEN, † D.N. HILL, T.N. CARLSTROM, D.G. NILSON† \\ R.E. STOCKDALE, C.L. HSIEH, T.W. PETRIE, A.W. LEONARD, \\ D. RYUTOV, † G.D. PORTER, ${ }^{\dagger}$ R. MAINGI, $¥$ M.R. WADE,, R. COHEN, $\dagger$ \\ W. NEVINS, ${ }^{\dagger}$ M.E. FENSTERMACHER, ${ }^{\dagger}$ R.D. WOOD, ${ }^{\dagger}$ C.J. LASNIER, ${ }^{\dagger}$ \\ W.P. WEST, and M.D. BROWN ${ }^{\dagger}$
}

This is a preprint of a paper to be presented at the 12th International Conference on Plasma Surface Interactions in Controlled Fusion Devices, May 20-24, 1996, Saint-Raphael, France and to be published in the Proceedings.

\author{
$\dagger_{\text {Lawrence Livermore National Laboratory }}$ \\ ¥Oak Ridge Associated Universities \\ Oak Ridge National Laboratory
}

Work supported by the U.S. Department of Energy

under Contract Nos. DE-AC03-89ER51114, W-7405-ENG-48, and DE-AC05-96OR22464

GA PROJECT 3466

OCTOBER 1996 


\section{ABSTRACT}

We have obtained the first measurements of $n_{e}$ and $T_{e}$ in the DIII-D divertor region with a multi-pulse $(20 \mathrm{~Hz})$ Divertor Thomson Scattering (DTS) system. Eight measurement locations are distributed vertically up to $21 \mathrm{~cm}$ above the divertor plate. Two-dimensional distributions have been obtained by sweeping the divertor plasma across the DTS measurement location. Several operating modes have been studied, including ohmic, L-mode, Elming $\mathrm{H}$-mode, and Radiative Divertor operation with puffing of $\mathrm{D}_{2}$ and impurities. Mapping of the data to either the $\left(\mathrm{L}_{\mathrm{pol}}, \phi\right)$ or $(\mathrm{R}, \mathrm{Z})$ planes with the EFIT equilibrium is used to analyze the 2D profiles. We find that in ELMing H-mode: $n_{e}, T_{e}$, and $\mathrm{P}_{e}$ are relatively constant along field lines from the $\mathrm{X}$-point to the divertor plate, especially near the separatrix field line. With $\mathrm{D}_{2}$ puffing, the DTS profiles indicate that $T_{e}$ in a large part of divertor region below the $X$-point is dramatically reduced from $\sim 30-40 \mathrm{eV}$ in ELMing $\mathrm{H}-$ mode to $1-2 \mathrm{eV}$. This results in a fairly uniform low- $\mathrm{T}_{\mathrm{e}}$ divertor, with an increased electron density in the range of 2 to $4 \times 10^{20} \mathrm{~m}^{-3}$.

Detailed comparisons of the spatial profiles of $n_{e}, T_{e}$, and electron pressure $P_{e}$, are presented for several operating modes. In addition, these data are compared with initial calculations from the UEDGE fluid code. 


\section{INTRODUCTION}

The divertor in a tokamak must exhaust heat, particles and also provide density and particle control for the plasma core. Currently, one approach to reduce the divertor heat load is to radiate the power in the SOL and divertor, thereby spreading the heat flux over a wider area (e.g. a "Radiative Divertor"). Significant heat flux reduction has been achieved with $\mathrm{D}_{2}$ [1-3] and impurity puffing [4] on DIII-D and other machines [5]. Particle exhaust of $\mathrm{D}_{2}$ [6] and helium [7] has also been demonstrated. While these techniques are promising on existing machines, we must assess the effectiveness of these techniques for future machines. This extrapolation requires that we must develop an understanding of the relevant physical processes, which can in turn be implemented in benchmarked computational codes [8]. These codes then become design tools for tokamak divertors in future machines (and in other devices with open field lines).

One of the important ingredients in achieving this understanding is the measurement of $n_{e}$ and $\mathrm{T}_{\mathrm{e}}$ in the divertor and scrape-off layer (SOL) during various operating modes. These are particularly important in radiating plasmas, as $n_{e}$ and $T_{e}$ determine the atomic physics processes. While time-resolved, detailed measurements of $n_{e}$ and $T_{e}$ with Thomson Scattering and other diagnostics [9] have become relatively routine in the core [10] and SOL [11,12], much of the data in the divertor has been obtained at the divertor plate with fixed probes [13] or at low injected power with scanning probes [14].

We present a short summary of the first Thomson Scattering measurements of $n_{e}$ and $T_{e}$ in a tokamak divertor. The divertor plasma was scanned past the Divertor Thomson Scattering (DTS) diagnostic to obtain 2-D profiles of the data. While data was obtained over a wide range of conditions during the Divertor Characterization Experiment (DCX) on DIII-D [15], we will focus here on results from ELMing $\mathrm{H}$-mode and $\mathrm{D}_{2}$ puffing. Other papers present detailed physics results $[16,17]$ and diagnostic details $[18,19]$.

After a short description of the DTS and it's relationship to other diagnostics, we present results from ELMing $\mathrm{H}-$ mode in Section 3, followed by $\mathrm{D}_{2}$ puffing results in Section 4 . A comparison of a measured 2-D $\mathrm{T}_{\mathrm{e}}$ profile with calculations from the UEDGE code are presented in Section 5 , followed by a discussion. 


\section{DESCRIPTION OF THE EXPERIMENTAL SETUP}

The DIII-D DTS system borrows heavily from the design of the DIII-D core Thomson Scattering system [10]. The locations of the measurement locations for the DTS are shown in the top of Fig. 1, where a cross-section of the lower DIII-D divertor is shown. (For orientation, the Advanced Divertor cryopump is shown at the right of Fig. 1.) The Nd:YAG laser beam enters the machine from below through a port in the middle of the divertor plate and the collection optics are focused along the laser beam at eight locations above the divertor plate. The centroids of the measurement locations are: $1.6 \mathrm{~cm}, 3.5 \mathrm{~cm}, 5.3 \mathrm{~cm}, 7.2 \mathrm{~cm}$, $10.8 \mathrm{~cm}, 14.2 \mathrm{~cm} 17.5 \mathrm{~cm}$, and $20.8 \mathrm{~cm}$ above the divertor plate. The radial extent of the measurement is determined by the size of the laser beam (about $0.3 \mathrm{~cm}$ ) and the height is determined by the viewing optics (about $1.3-1.5 \mathrm{~cm}$, depending on channel). The measurement time during the laser pulse is very short (15 ns), and the laser pulses every $50 \mathrm{~ms}$ during the discharge. The major changes in the DTS system compared to the core system were: 1 ) a specially designed, aspherical wide-aperture ( $f / 6.8)$ collection lens, 2) polychromators optimized for low temperature measurements [19], and 3) a stray light reduction scheme optimized for the divertor geometry [18]. The design features have enabled measurement of $T_{e}$ in the range $\leq 1 \mathrm{eV}$ in the presence of the ambient background of plasma radiation.

We obtain the most interesting and useful DTS measurements under two conditions: 1) fixed divertor plasma position, with a variation of the plasma parameters, and 2) swept divertor plasma position with constant plasma conditions. An example of case 1 is the detailed study of Partially Detached Discharges (PDD-detached at the separatrix, and reattached away from the separatrix at the divertor plate) obtained during Radiative Divertor operation with $D_{2}$ puffing [17]. The measured $T_{e}$ over most of the DTS channels drops significantly and the divertor heat flux is reduced by factors of 3-5. Case 2 involves maintaining the plasma in ELMing $\mathrm{H}$-mode or PDD mode while the 2-D distribution of $\mathrm{T}_{\mathrm{e}}$ and $n_{e}$ is obtained; this case is the focus of the present discussion.

Shown in the Fig. 1 is the time history of a typical ELMing H-mode discharge (86885) with a sweep of the divertor plasma. The discharge parameters were: lower single null, plasma current $\mathrm{I}_{\mathrm{p}}=1.4 \mathrm{MA}$, toroidal field $\mathrm{B}_{\mathrm{T}}=2.1 \mathrm{~T}$ ( $\nabla \mathrm{B}$ drift towards the divertor), neutral beam power $P_{i n j}=4.1 \mathrm{MW}$, and core plasma density $n_{e}=6.5 \times 10^{19} \mathrm{~m}^{-3}$. The core plasma conditions were held fixed as the radial locations of the strike point on the divertor plate (third panel of Fig. 1) and the $X$-point (fourth panel) were swept in time. The $T_{e}(10.8 \mathrm{~cm}$ above the divertor plate-first panel of Fig. 1) and $n_{e}(7.2 \mathrm{~cm}$ above the divertor plate-second panel of 

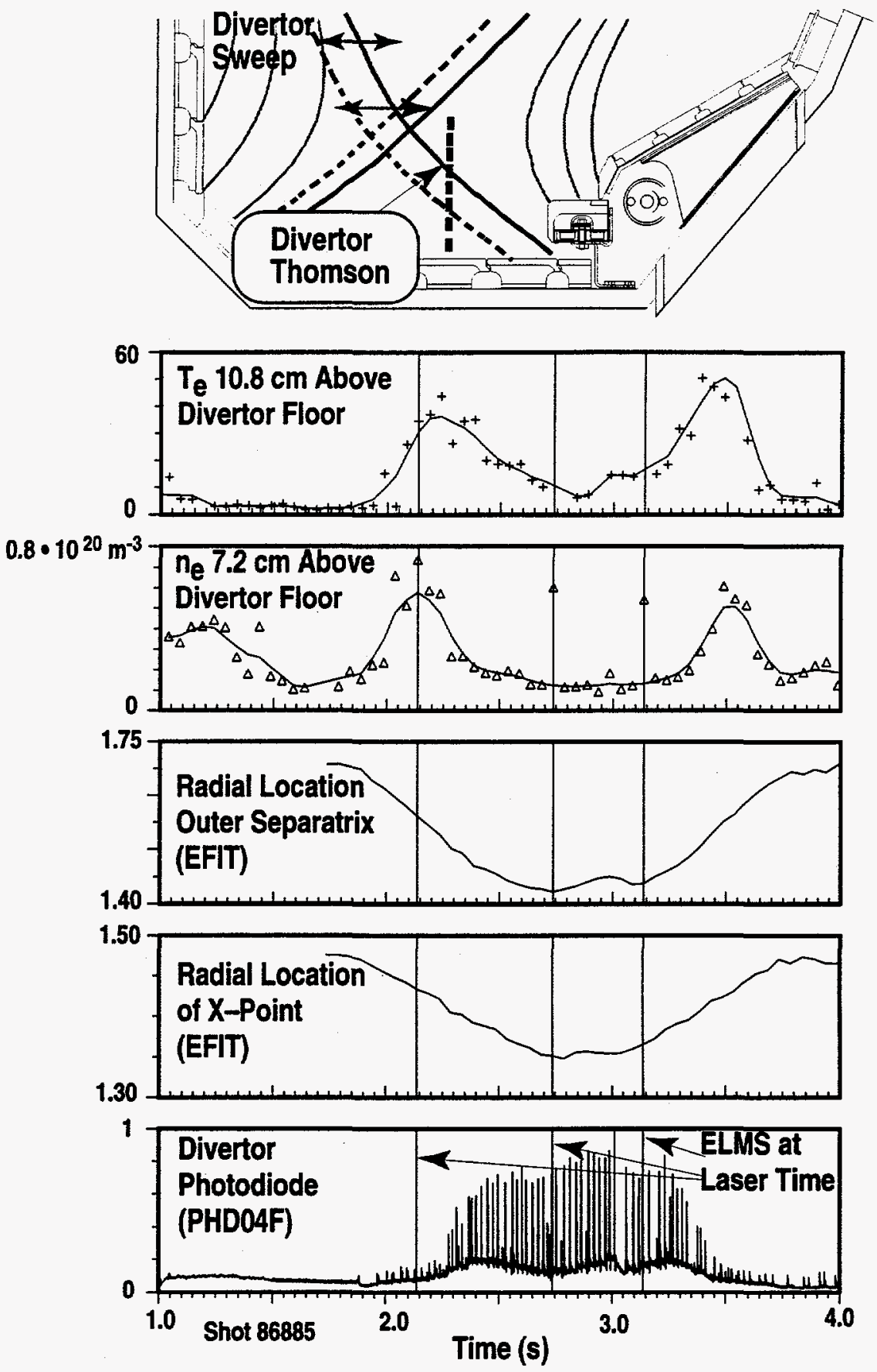

Fig. 1. (Top) A cross-sectional view of the lower DIII-D divertor, showing the measurement locations of the DTS. For reference, the cryopump is at the right side of the figure. (Bottom) 2-D measurements are obtained by sweeping the divertor plasma. Several time histories are presented: $T_{e}$ at $10.8 \mathrm{~cm}$ above the floor, $n_{e}$ at $7.2 \mathrm{~cm}$ above the floor, $R_{\text {sep }}(t)$-the outer separatrix position, $R_{x p t}(t)$-the $X$-point radial position, and a photodiode signal. The vertical lines show where ELMs were coincident with the DTS laser firing, these data have been excluded from the analyses. (Shot 86885) 
Fig. 1) from DTS are shown. The ELM frequency on this shot was low enough that nearly all of the DTS times were between ELMs. However, there are three time locations noted in Fig. 1 when an ELM was coincident with the DTS firing time, and there is a large change in the measured $n_{e}$ ( $T_{e}$ was not plotted for these times). We find that the ELM "penetration" into the divertor varies, i.e., on some shots the ELM perturbs all of the DTS channels, and on others, it perturbs only the upper few. There is usually a larger change in $n_{e}$ than in $T_{e}$. A detailed treatment of ELMs and DTS is beyond the scope of the present discussion; for the processing described here, we have removed the time points with ELM effects.

We also developed special divertor sweep patterns for these experiments [20]. We started with experiments that kept the $\mathrm{X}$-point height relatively fixed, and allowed the poloidal length $\mathrm{L}_{\text {pol }}$ from the $\mathrm{X}$-point to divertor plate to vary somewhat. Special control algorithms were developed from analysis of experimental sweeps so that we could keep the poloidal length (X-point to plate) constant, and allow the $\mathrm{X}$-point height to vary somewhat. The details of these sweeps can be important, as some physics in the divertor may be sensitive to absolute lengths (i.e., neutral penetration) as opposed to field line lengths (i.e., charged particle effects). For the data presented here, there were no large variations in poloidal length and only relatively minor variations in $\mathrm{X}$-point height. 


\section{DTS PROFILES DURING ELMING H-MODE OPERATION}

We present the data from two similar ELMing H-mode shots (86885-86886) in Fig. 2 . About 550 DTS measurements of $n_{e}$ and $T_{e}$ were obtained between ELMs on the two shots. $A$ computer algorithm uses the EFIT equilibrium reconstruction calculated at each DTS time to map the $\mathrm{n}_{\mathrm{e}}$ and $\mathrm{T}_{\mathrm{e}}$ data. In Fig. 2, we have mapped the data to a new coordinate plane consisting of the poloidal length from the divertor plate $\left(\mathrm{L}_{\mathrm{pol}}\right)$ and normalized flux $(\phi=1$ is the separatrix, $\phi>1$ is the SOL, $\phi<1$ is the core, the straight vertical lines are flux surfaces).
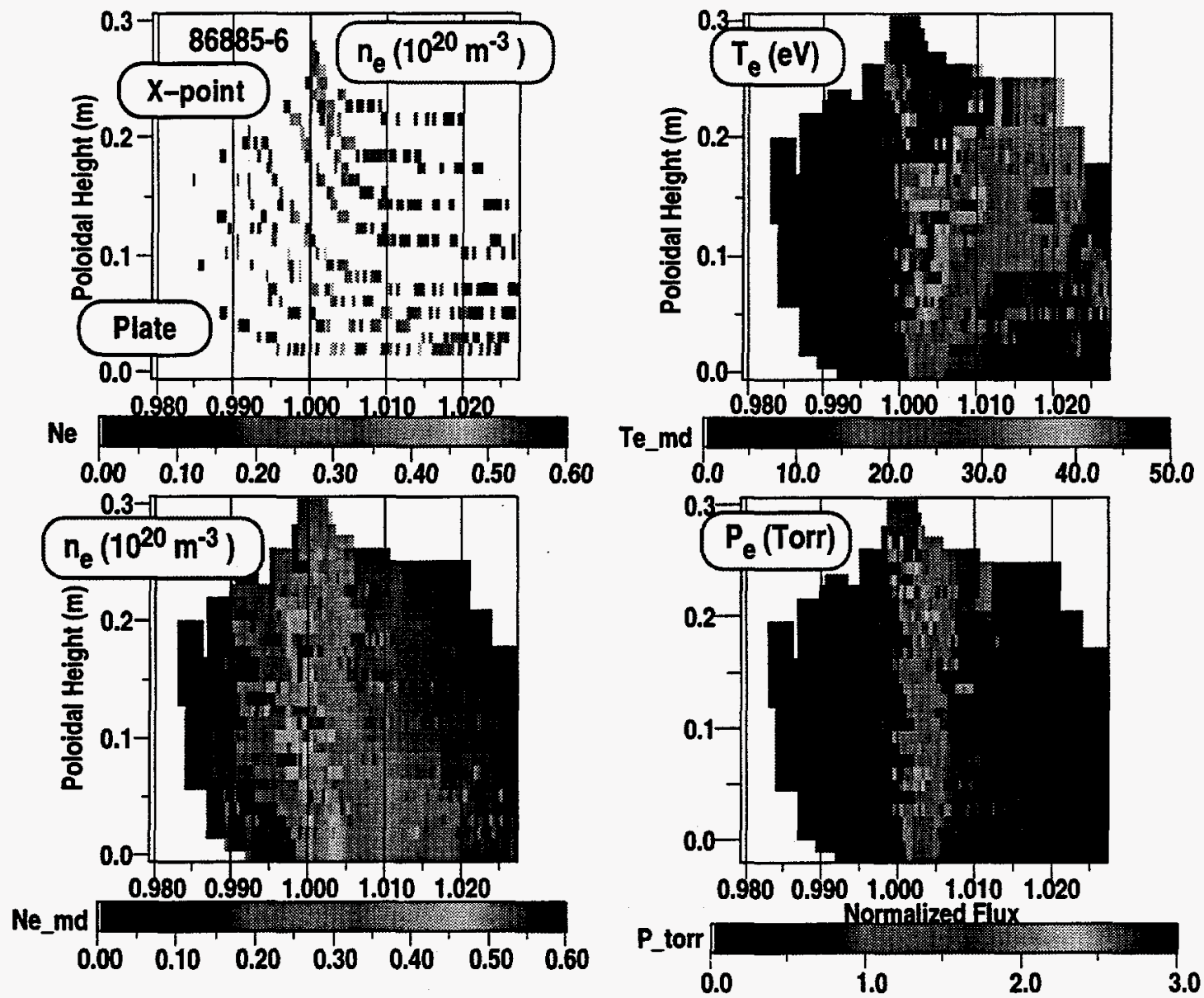

Shots $86885-6$

Fig. 2. Representative DTS data from an ELMing $\mathrm{H}$-mode. (top) The DTS data points are mapped with EFIT onto a coordinate system of the poloidal length and the normalized flux ( $\phi=1$ is the separatrix, the $X$-point is at a $L_{p o l}$ of about $\left.0.2 \mathrm{~m}\right)$. These data are then smoothed; the $n_{e}, T_{e}$ and $P_{e}$ profiles are shown. Note that these quantities are relatively constant along field lines from the $X$-point to the divertor. 
The $\mathrm{L}_{\text {pol }}$ from the $\mathrm{X}$-point to the divertor plate for these discharges was about $20 \mathrm{~cm}$. In Fig. 2, we have used the actual $\mathrm{L}_{\text {pol }}$ in the mapping (we can also use the $\mathrm{L}_{\text {pol }}$ normalized to $\mathrm{L}_{\text {pol }}$ from the $\mathrm{X}$-point to the divertor plate; for this data set it would not make a significant difference).

The top frame of Fig. 2 shows $n_{e}$ as a function of $L_{p o l}$ and $\phi$. We have represented the data points on a grid which roughly corresponds to the spatial extent of each data point. We have not smoothed these data, except when two data points occur in the same cell, and in this case we have displayed the average. The second frame shows a smoothed version of these $n_{e}$ data. The original data points are still plotted, but a smoothing function that drops off as the square of the distance from the data point has been used to fill in missing data; the three nearest cells are used in the algorithm. Note the high $n_{e}$ region that extends down the separatrix field line from the $\mathrm{X}$-point to the plate. The smoothed $\mathrm{T}_{\mathrm{e}}$ data (third frame) also have a peak $(-30-40 \mathrm{eV})$ in $\mathrm{T}_{\mathrm{e}}$ near the separatrix, with a similar profile. Finally, in the last frame we plot the smoothed electron pressure $P_{e}$, which is the product of $n_{e}$ and $T_{e}$. This is an "attached" ELMing H-mode plasma case, and we note that $\mathrm{P}_{\mathrm{e}}$ is relatively constant down the flux surface. Detailed comparisons of the total divertor pressure (assuming $\mathrm{P}_{\mathrm{e}}$ equals $\mathrm{P}_{\mathrm{i}}$ ) with the midplane (measured $P_{e}$ and $P_{i}$ ) pressure normally show agreement to within a factor of 2 , a detailed discussion of electron pressure balance is presented in [17]. (In passing, it should be noted that the difference between the peak of the data in each case and the location of the separatrix in each frame is probably within the uncertainty in the EFIT reconstruction (estimated to be about $1 \mathrm{~cm}$ at the divertor plate (Fig. 3); we are currently looking at this in detail.) 


\section{COMPARISON OF DTS PROFILES IN ELMING H-MODE WITHOUT- AND WITH-(PDD) D2 GAS PUFFING}

In addition to the $\mathrm{L}_{\text {pol }}$ and $\phi$ plots shown in Fig. 2, it is also useful to map the data to a representative equilibrium and display it in real spatial (major radius, height) coordinates. In Fig. 3 (left side) we show the same data as in Fig. 2 except we have mapped the data to the plasma equilibrium at $3687 \mathrm{~ms}$. On the right half of Fig. 3 we show the data from a series of ELMing $\mathrm{H}$-mode discharges with $\mathrm{D}_{2}$ puffing, (discharges 87638, 87639, and 87642 mapped to $2837 \mathrm{~ms}$ ). The discharge parameters are similar to the ELMing $\mathrm{H}$-mode shots without puffing shown in the left half of the figure, although the density is increased and the injected power is decreased somewhat $\left(I_{p}=1.4 \mathrm{MA}, P_{i n j}=4 \mathrm{MW}, B_{T}=2.1 \mathrm{~T}\right.$, core $\left.n_{e}=8 \times 10^{19} \mathrm{~m}^{-3}\right)$. Each pair of plots has the same scale except for $n_{e}$, which is over four times greater in the detached case. (Some red data points in the core have been suppressed so that we can focus on the divertor and SOL.) Note the band of increased density located outside of the separatrix that extends towards the divertor plate. The density in this region has increased by nearly an order of magnitude compared to the figure on the left. The $T_{e}$ is dramatically reduced over a large extent of the divertor. The electron pressure drops from the $\mathrm{X}$-point to the divertor plate, and the pressure is greatly reduced near the separatrix.

Careful examination of the $T_{e}$ data points in these and other detached discharges has indicated very low temperatures near the separatrix, i.e. $\mathrm{T}_{\mathrm{e}}<2 \mathrm{eV}$. The raw data has been checked to verify that these are valid temperature measurements. This result is important as new atomic processes such as volume recombination may be important at these temperatures. We are currently examining the relationship between the radiation profiles observed in these discharges with the zones of reduced temperature. 

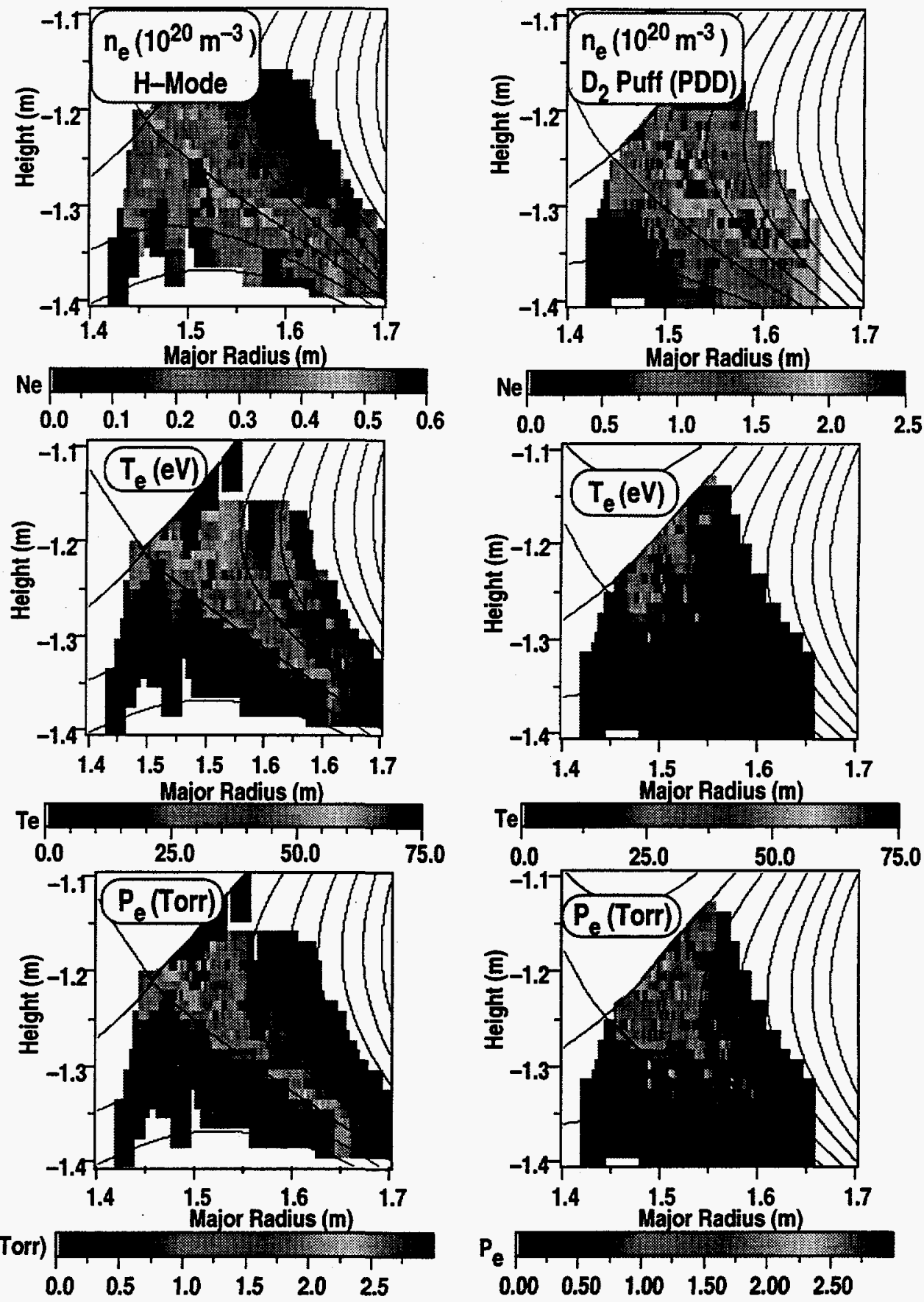

Fig. 3. The DTS data mapped to spatial coordinates using a representative EFIT equilibrium during the shot. (left) The same data as in Fig. 2 for an ELMing $\mathrm{H}$-mode are shown mapped to the $R$ (major radius) and $Z$ (height) plane. These data are compared with a $D_{2}$ puffing shot shown on the right. All the scales are the same except for $n_{e}$, which is increased by $\sim 4$. The density is dramatically increased for the detached case; note the region outside of the separatrix which increases by nearly an order of magnitude. The $T_{e}$ is dramatically reduced, with some data points $T_{e}=1 \mathrm{eV}$. 


\section{COMPARISON WITH UEDGE MODEL}

We have also started preliminary comparisons of the 2-D DTS results with 2-D computations from the UEDGE model. A comparison is shown in Fig. 4, where the measured (top) and UEDGE-calculated (bottom) $\mathrm{T}_{\mathrm{e}}$ are shown with the same scales (Shot 86586, ELMing $\mathrm{H}$-mode with $\mathrm{P}_{\text {inj }} \sim 7 \mathrm{MW}$ ). The UEDGE code was matched to the measured upstream (midplane) conditions, and it has reproduced most of the general features of the measured $T_{e}$. However, a detailed comparison of the $T_{e}$ data in a flux tube near the separatrix indicates that the data falls off more rapidly from the $\mathrm{X}$-point to the divertor plate than the UEDGE model. This may be due to details of the radiating zone not modeled in UEDGE (a constant impurity fraction was used). In addition, we find that the measured $\mathrm{H}_{\alpha}$ emission in the private flux region is greater than the UEDGE calculation. We are currently focusing on better representations of the radiation (impurity and hydrogenic) in the code, including several impurity models. These are crucial to understanding the PDD and impurity-injected Radiative Divertor modes. 


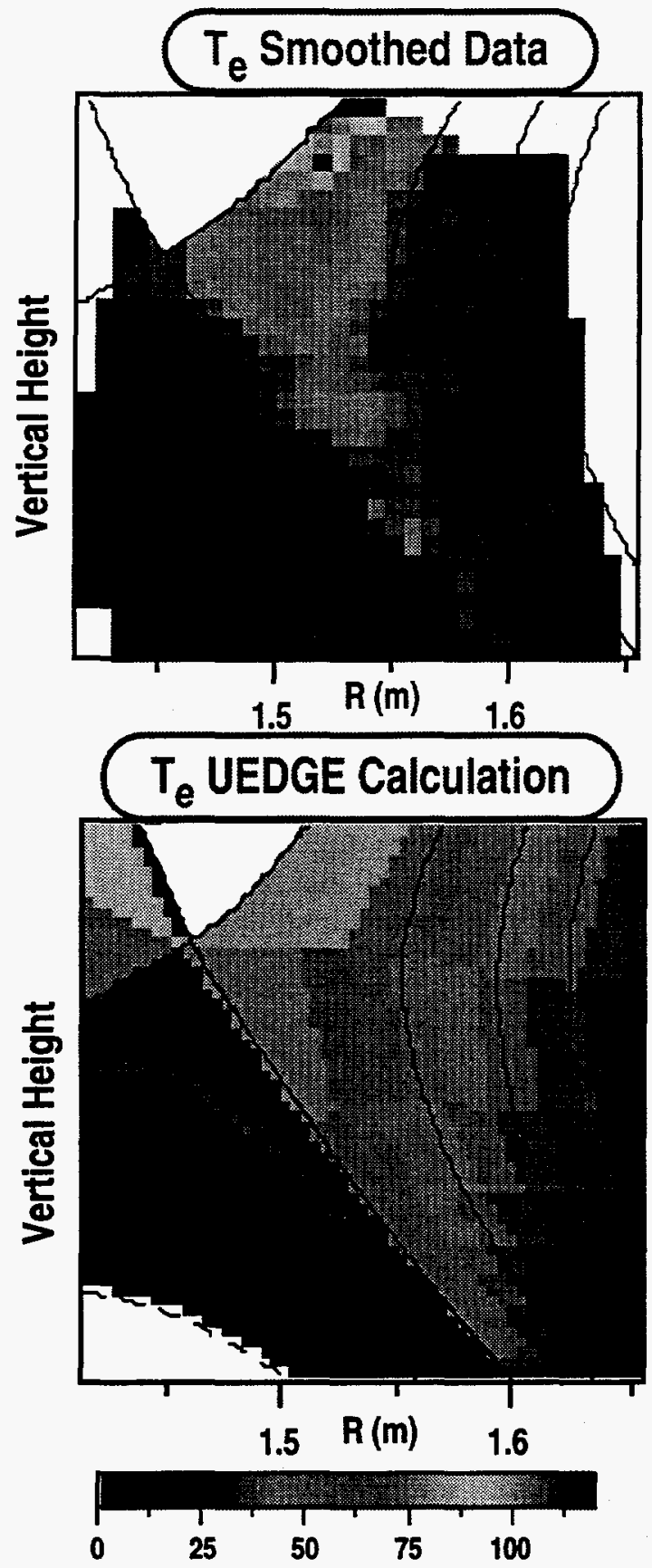

Shot 86586 Electron Temperature (eV)

Fig. 4. A comparison of the smoothed DTS $T_{e}$ data (top) with an initial calculation from UEDGE. There is relatively good agreement between the data and the code. Improvements in the impurity transport treatment in UEDGE is expected to improve the comparison. 


\section{DISCUSSION}

The first measurements from the DTS have provided important data for the physics understanding of the divertor. A large amount of data under various discharge conditions has been obtained; we have presented only ELMing $\mathrm{H}$-mode discharges with- and without- gas puffing here. The $n_{e}$ increases dramatically in a PDD discharge, while the $T_{e}$ and $P_{e}$ drop. Measurements of $\mathrm{T}_{\mathrm{e}} \leq 1$ have been observed during PDD operation. In most of the detached discharges studied (both the detached discharge shown in Fig. 3 and L-mode (not shown) with $\mathrm{D}_{2}$ puffing), the peaking of the density somewhat outside of the separatrix and dramatically reduced $T_{e}$ was a common signature. In general, it was found that some trends in the 2-D data tended to follow field lines (e.g., Fig. 2), while others did not (e.g., $\mathrm{n}_{\mathrm{e}}$ on the right side of Fig. 3, a $D_{2}$ gas puffing case; this is seen more clearly in a plot of $n_{e}$ as a function of $L_{\text {pol }}$ and $\phi$ ), suggesting the importance of neutral particle effects. The present analyses have focused on the time period between ELMs; we are currently characterizing the ELM time periods, where $n_{e}$ in the divertor may be further increased. Future studies will focus on the relationship between the $T_{e}$ and $n_{e}$ profiles to the 2-D distribution of radiation and impurities. 


\section{REFERENCES}

[1] T. W. Petrie, et al., in Proc. of 18th Euro. Conf. on Contr. Fusion and Plasma Physics (European Physical Society, Petit-Lancy, Switzerland, Berlin, Germany, 1991), Vol. 3, p. 237.

[2] T.W. Petrie, et al., Journ. Nuc. Mat. 196-198, 848 (1992).

[3] T.W. Petrie, et al., Radiative Divertor Experiments in DIII-D with Deuterium Injection, to be published in Nuclear Fusion, General Atomics Report GA-A21879 (1995).

[4] S.L. Allen, N.H. Brooks, R.B. Campbell, et al., Journ. Nuc. Mat. 220-222, 336 (1995).

[5] H.-S. Bosch, D. Coster, R. Dux, et al., "Particle Exhaust in Radiative Divertor Experiments:, to be published in these proceedings.

[6] R. Maingi, et al., Divertor Particle Exhaust and Wall Inventory on DIII-D, to be published in these proceedings (1995).

[7] M.R. Wade, D.L. Hillis, J.T. Hogan, et al., Phys. Rev. Lett. 74, 2702 (1995).

[8] G. Porter, et al., Analysis of SOL and Divertor Behavior in DIII-D, to be published in Proceedings of the European Physical Society (1996).

[9] J.G. Watkins, et al., Rev. Sci. Instrum. 63, 4728 (1992).

[10] T.N. Carlstrom, G.L. Campbell, J.C. DeBoo, et al., Rev. Sci. Instrum. 63, 4901 (1992).

[11] J.G. Watkins, et al., Journ. Nuc. Mat. 220-222, 347 (1994).

[12] N. Asakura, Y. Koide, K. Itami, et al., "SOL Plasma Profiles under Radiative and Detached Divertor Conditions in JT-60U, to be published in these proceedings.

[13] D. Buchenauer, et al., Rev. Sci. Instrum. 61, 2873 (1990).

[14] J.G. Watkins, J. Hunter, B. Tafoya, et al., A Fast Reciprocating Langmuir Probe for the DIII-D Divertor, to be published in these proceedings (1996).

[15] M.E. Fenstermacher, R.D. Wood, S.L. Allen, et al., Comprehensive 2D Measurements of Radiative Divertor Plasmas in DIII-D, to be published in these proceedings (1996).

[16] D.N. Hill, et al., First Measurements of ne and Te in the DIII-D Divertor Plasma, to be published in Physical Review Letters (1996).

[17] T.W. Petrie, S.L. Allen, T.N. Carlstrom, et al., Investigation of Electron Parallel Pressure Balance in the Scrapeoff Layer of Deuterium-Based Radiative Divertor Discharges in DIII-D, to be published in these proceedings (1996).

[18] D.G. Nilson, N.H. Brooks, J.P. Smith, et al., Divertor Thomson Scattering on DIII-D, to be published in Fusion Engineering and Design (1996).

[19] T.N. Carlstrom, D.G. Nilson, D. Hill, et al., Initial Operation of the Divertor Thomson Scattering Diagnostic on DIII-D, to be published in Proceedings of the $11^{\text {th }}$ 
FIRST MEASUREMENTS OF ELECTRON TEMPERATURE AND DENSITY WITH DIVERTOR THOMSON SCATTERING IN RADIATIVE DIVERTOR DISCHARGES

ON DIII-D

International Conference on High Temperature Plasma Diagnostics, Monterey, CA (1996).

[20] A.W. Leonard, Private Communications, May, 1996. 


\section{ACKNOWLEDGMENTS}

This work has been a team effort, including engineering, technical, and computations support in addition to the Physics analysis. Work supported by U.S. Department of Energy under Contract DE-AC03-89ER51114 (GA), W-7405-ENG-48 (LLNL) and DE-AC0596OR22464 (ORNL). 